\title{
The effect of mucins on initiating reductive acetogenesis in vitro
}

\author{
D Fiedler 2, I Immig 1, C Van Nevel 3, D Demeyer 3 \\ 1 nstitute of Applied Animal Science, Humboldt University Berlin, 14195 Berlin, Germany \\ ${ }^{2}$ Forschungsinstitut für die Biologie landwirstschaflicher Nutztiere, 18059 Rostock, Germany \\ 3 Onderzoekscentrum voor Voeding, Veelteet en Vleestechnologie, $9230 \mathrm{Melle}$, Belgium
}

Hindgut fermentation in a number of animal species differs from rumen fermentation by showing a substantially lower methane production and the presence of reductive acetogenesis. Strong competition between methanogenic and acetogenic bacteria for metabolic hydrogen seems to be responsible for the lack of reductive acetogenesis in the rumen. One factor causing a nonmethanogenic pathway in the hindgut and acetate as the reduced end product could be the presence of endogenous mucins which are not present in the rumen. The replacement of methane by acetate as a hydrogen sink should increase the energy yield available for the ruminant and decrease methane emissions, and thus be benefit to the animal and the environment. The aim of this experiment was to investigate the influence of mucins on reductive acetogenesis in vitro.

Rumen fluid from a canulated sheep was incubated with a buffer solution under anaerobic conditions (incubation gas: $\mathrm{CO}_{2}$, $24 \mathrm{~h}, 39^{\circ} \mathrm{C}$ ). Substrates were $500 \mathrm{mg}$ hay, 500 $\mathrm{mg}$ mucin or $500 \mathrm{mg}$ hay $+500 \mathrm{mg}$ mucin. To test for reductive acetogenesis, hydrogen gas was added $(50 / 50 \mathrm{v} / \mathrm{v})$ to half of the flasks. After incubation, methane and SCFA production were measured by gas chromatography.

Mucins enhanced methanogenesis from $464 \mu \mathrm{mol} / \mathrm{d}$ to $727 \mu \mathrm{mol} / \mathrm{d}$. Due to a substantially higher SCFA production the amount of $\mathrm{CH}_{4}$ produced decreased from 269 to 148 $\mathrm{mmol} \mathrm{CH}_{4} / \mathrm{mol}$ SCFA. Fermentation stoichiometry was calculated using the net amounts of end products formed from hay in the presence and absence of mucins. Neither the values obtained for hydrogen recovery, nor the effects of head space hydrogen on acetate production suggest enhancement of reductive acetogenesis. We conclude that in our experiments mucins did not stimulate reductive acetogenesis.

\begin{tabular}{lccccccc} 
& \multicolumn{4}{c}{ Production $(\mu \mathrm{mol})$} & & $\begin{array}{c}\mathrm{CH}_{4} \\
(\mathrm{mmol} / \mathrm{mol} \\
\text { SCFA })\end{array}$ & $\begin{array}{c}\mathrm{H}_{2} \\
\text {-recovery } \\
(\%)\end{array}$ \\
\cline { 2 - 5 } & Acetate & Propionate & Butyrate & $\mathrm{CH}_{4}$ & & \\
\hline $\mathrm{RF}+500 \mathrm{mg}$ & 1189 & 391 & 113 & 464 & 266 & 89 \\
hay & 91 & 13 & 8 & 88 & & \\
$\mathrm{RF}+500 \mathrm{mg}$ & 1923 & 674 & 172 & 371 & 126 & 61 \\
mucins & 65 & 67 & 16 & 49 & & \\
$\mathrm{RF}+500 \mathrm{mg}$ hay & 3158 & 1186 & 327 & 727 & 148 & 66 \\
$+500 \mathrm{mg}$ mucins & 205 & 32 & 26 & 69 & & \\
\hline
\end{tabular}

